\title{
Web-based Physical Activity Interventions for Older Adults: A Review
}

\author{
Hazwani Mohd Mohadis ${ }^{1}$, Nazlena Mohamad Ali ${ }^{1}$, Suzana Shahar ${ }^{2}$ and Alan F. \\ Smeaton ${ }^{3}$, \\ ${ }^{1}$ Institute of Visual Informatics, Universiti Kebangsaan Malaysia, 43600 Bangi, Selangor, \\ Malaysia \\ hazwanimohadis@gmail.com, nazlena.ali@ukm.edu.my \\ ${ }^{2}$ Faculty of Health Sciences, Universiti Kebangsaan Malaysia, 50300 Kuala Lumpur, \\ Malaysia \\ suzanas@ukm. edu.my \\ ${ }^{3}$ Insight Centre for Data Analytics, Dublin City University, Glasnevin, Ireland \\ alan. smeatonedcu.ie
}

\begin{abstract}
Most web-based physical activity interventions were built based on the principles of universal design but may have overlooked age-related impairments experienced by older adults. Thus, it is important to know how successful such web-based interventions are in enhancing older adults' physical activity levels despite these shortcomings. The objective of this study is to review published literature regarding interactive web-based interventions promoting physical activity among older adults. EBSCOhost, ISI Web of Science and ScienceDirect databases were searched to identify relevant peerreviewed papers. Results were summarized in a qualitative way. We included 15 papers reporting on web-based interventions with physical activity components. Ten and two studies respectively indicated positive and negative outcomes, while the outcomes of the remaining three studies are unclear. Despite the fact that computer illiteracy and age-related impairments can both be experienced, there is preliminary evidence that suggests that web-based interventions are effective in encouraging physical activity among older adults.
\end{abstract}

Keywords: Web-based intervention, physical activity, older adults, behaviour change

\section{Introduction}

Research has shown that approximately $30 \%$ to $50 \%$ of the Malaysian government total healthcare spending goes towards the care of older adults [1]. Such substantial i proportion of healthcare costs has been attributed to a high prevalence of chronic diseases among Malaysian older adults, such as diabetes, cardiovascular disease and hypertension, which have been gradually increasing each year [2]. Thus, with healthcare costs being the fastest-growing government expenditure, there is enormous 
pressure for public health to become more cost efficient and effective [3]. One potential solution to reduce the high cost of curative care is to institute patient empowerment, where older adults actively participate in their own health management and treatment [3]. In order to enhance understanding and awareness of their own healthcare, technological interventions driven by today's Internet and web advancements can be utilized [4]. Further, as clinical research suggests that an increase in physical activity may contribute to prevention of chronic diseases and subsequently promote healthy aging, it is vital for us to manipulate the advances in web technology to encourage physical activity among older adults [5]. Additionally, such internet-mediated interventions would not only have immense potential for the implementation of effective lifestyle programs at very low cost but also be capable of reaching large populations of older persons [6,7].

Although a large amount of research has proven that the use of assistive technologies and information communication technologies (ICTs) which in particular address the physical, cognitive and social aspects of ageing, have the potential to encourage more physical activities among older adults and subsequently increase their quality of life [8], previous studies published within the past few years show a lower degree of technology adoption due to physical, cognitive and/or sensory problems which can cause interactions with a user interface to become difficult and cumbersome [7,9]. This is because good visual and motor coordination that many older adults no longer possess is indeed crucial for them to read and comprehend displayed information as well as selecting links to other web pages, for example [10]. Meanwhile, on a positive note, some studies reveal that despite their age-related impairments, older adults still declare a great willingness to learn and to receive education and information that may help to improve their health [11]. This indicates that there is high potential in the utilization of computers and the Internet as a medium for effective intervention for a healthier lifestyle among older adults.

This review paper specifically aims to identify: 1) state of the art in web-based physical activity interventions, and 2) current practices in designing and evaluating the efficacy of web-based interventions aiming to encourage physical activity among older adults.

\section{Methods}

EBSCOhost, ISI Web of Science and Science Direct electronic journal databases were searched using the following keywords; (1) web, online, Internet (2) physical activity, exercises (3) elderly, older adult, in order to identify relevant studies. An article was included in our review if it was a peer-reviewed full research article in English published between January 1, 2009 and December 31, 2013 (5-year range). The intervention was deemed an interactive web-based system involving older adult users as study participants if it included at least one subjective (e.g. self-reported physical activity questionnaire) or objective measurement (e.g. accelerometer data) assessing physical activity levels. General web-based health interventions targeting older adults 
without physical activity components or a physical activity intervention without older adult involvement was excluded. The inclusion criteria were first applied to the titles and abstracts of articles. If the abstract was found to be relevant, the full publication was reviewed. A total of 15 eligible articles were finally selected [12 - 26]. For each selected articles, study characteristics (authors, year of publication, country, aim, and study design), intervention characteristics, physical activity measurement(s) and outcome were extracted.

\section{Results}

More studies were conducted in the recent 2 years (2012-2013) compared to preceding years, indicating an increasing interest among researchers in the development of web-based physical activity interventions for older adults. Those identified studies were mainly conducted in the Netherlands $(n=7)$ and the United States $(n=5)$, while the remaining three studies each were each conducted in Sweden, United Kingdom and Italy.

As shown in Table 1 below, the objective of each selected study varies greatly. Out of fifteen studies, only five specifically aim to investigate the efficacy of the interventions in increasing the level of physical activity among participants [12, 13, $14,15,16]$. Another six studies aim to investigate the effectiveness of design components in encouraging physical activity [17, 18, 19, 20, 21, 22]. Albaina et al. [17] for example aims to evaluate persuasive design principles and interaction metaphors in Flowie, a persuasive virtual coach that encourages seniors to walk more. Silveira et al. [21] focuses on the efficacy of motivational elements in ActiveLifestyle, whilst Hughes et al. [20] on the efficacy of online consultation. Nyman et al. [18], Pekmezi et al. [19] and Amman et al. [22] on the other hand specifically focus on the acceptability of tailored advice components in enhancing physical activity. Besides these, another three studies aim to identify user characteristics of the interventions. Peels et al. [23] for example investigate user characteristics related to participation and attrition in both web-based and print-delivered interventions, Schneider et al. [24] aim to identify user characteristics that predict initiation and completion of the module, while Schulz et al. [25] involved assessment of user characteristics associated with the completion rates of the two interventions being studied (sequential and simultaneous condition). The remaining one study aimed to examine older adults' performance in using a behavioural weight loss program compared to younger adults [26].

In terms of study design, 10 studies conducted randomized controlled trials (RCT) with varied durations, ranging from 6 weeks $(n=1), 3$ months $(n=2), 6$ months $(n=1), 7$ months $(n=1), 10$ months $(n=1)$, and 12 months $(n=3)$. The duration of one RCT however was not specifically mentioned [25]. One study conducted a clustered RCT (cRCT) for 3 months while the remaining four non-RCT studies involved longitudinal study for 6 months $(n=1)$, one-month web evaluation $(n=1), 2$ weeks pilot study $(n=1)$ and 11 days prototype testing $(n=1)$.

Diverse types of measurements have been used across studies, which can be classified into objective measurements and subjective measurements. Examples of 
objective measurements used in these identified studies include the use of RT3 accelerometer [12], ActiPED pedometer [17] or ankle/wrist-work accelerometer [16]. Subjective measurements used, on the other hand, include self-reported 7-Day Physical Activity Recall (7-D PAR) [12, 19], Dutch Short Questionnaire to Assess Health Enhancing Physical Activity (SQUASH) [23, 24, 25] and validated Physical Activity Scale for the Elderly (PASE) [14].

Table 1. Study aims and corresponding physical activity measurements utilized

\begin{tabular}{|c|c|c|}
\hline Study & Aims & Physical Activity Measurements \\
\hline$[12]$ & $\begin{array}{l}\text { To determine the feasibility of } \\
\text { delivering a physical activity } \\
\text { intervention via the Internet on a } \\
\text { desktop computer to increase physical } \\
\text { activity and ultimately to improve } \\
\text { outcomes in the metabolic syndrome } \\
\text { population }\end{array}$ & $\begin{array}{l}\text { 1) 7-Day Physical Activity Recall (7-D } \\
\text { PAR). 2) RT3 accelerometer data: to } \\
\text { determine total energy expenditure and } \\
\text { to evaluating the validity of self- } \\
\text { reported 7-D PAR. 3) Cardiorespiratory } \\
\text { fitness (VO2max) data: indicators of } \\
\text { PA adherence. }\end{array}$ \\
\hline [13] & $\begin{array}{l}\text { To investigate usage and effectiveness } \\
\text { of the Healthy Weight Assistant } \\
\text { (HWA), to increase healthy behaviour } \\
\text { in adults with a healthy weight or } \\
\text { slightly overweight. }\end{array}$ & $\begin{array}{l}\text { Physical activity behaviour was } \\
\text { measured according to the Dutch } \\
\text { Standard for Healthy Physical Activity, } \\
\text { using a 4-item questionnaire. }\end{array}$ \\
\hline [14] & $\begin{array}{l}\text { To investigate whether a web-based } \\
\text { physical activity intervention for } \\
\text { patients with knee and/or hip } \\
\text { osteoarthritis would result in improved } \\
\text { levels of physical activity, physical } \\
\text { function and self-perceived effect. }\end{array}$ & $\begin{array}{l}\text { 1) Using validated Physical Activity } \\
\text { (PA) Scale for the Elderly (PASE) 2) } \\
\text { ActiGraph GT3X tri-axial } \\
\text { accelerometers to support self-reported } \\
\text { PASE data. }\end{array}$ \\
\hline [15] & $\begin{array}{l}\text { To evaluate the efficacy of a } 12 \text {-week } \\
\text { Internet intervention to help sedentary } \\
\text { older adults over } 55 \text { years of age adopt } \\
\text { and maintain an exercise regimen. }\end{array}$ & $\begin{array}{l}\text { Current activity level was measured } \\
\text { with 2-item sets, addressing the } \\
\text { frequency and duration of intentional } \\
\text { physical activities. Items were scored to } \\
\text { reflect minutes/week of each activity. }\end{array}$ \\
\hline [16] & $\begin{array}{l}\text { To assess whether a Web-based } \\
\text { intervention increases physical activity } \\
\text { and improves metabolic health in } \\
\text { inactive older adults. }\end{array}$ & $\begin{array}{l}\text { Measured objectively using ankle and } \\
\text { wrist-worn accelerometers. }\end{array}$ \\
\hline [17] & $\begin{array}{l}\text { To evaluate persuasive principles and } \\
\text { interaction metaphors with a user panel. }\end{array}$ & $\begin{array}{l}\text { Using the ActiPED pedometer data, } \\
\text { which automatically registers activity } \\
\text { levels up to } 21 \text { days }\end{array}$ \\
\hline [18] & $\begin{array}{l}\text { To evaluate a website providing } \\
\text { tailored advice to encourage older } \\
\text { people to undertake strength and } \\
\text { balance training (SBT). }\end{array}$ & $\begin{array}{l}\text { Self-report of SBT (Strength \& Balance } \\
\text { Training) }\end{array}$ \\
\hline [19] & $\begin{array}{l}\text { To examine the feasibility and efficacy } \\
\text { of } 3 \text { physical activity interventions } \\
\text { (Tailored Internet, Tailored Print, } \\
\text { Standard Internet) among African } \\
\text { American participants. }\end{array}$ & $\begin{array}{l}\text { 7-Day Physical Activity Recall (7-D } \\
\text { PAR), an interview on estimate of } \\
\text { weekly minutes of physical activity, } \\
\text { uses multiple strategies for increasing } \\
\text { accuracy of recall. }\end{array}$ \\
\hline [20] & To examine the effects of 2 work & Self-reported questionnaire using 7- \\
\hline
\end{tabular}




\begin{tabular}{|c|c|c|}
\hline & $\begin{array}{l}\text { health-promotion } \\
\text { (compared with a health-education } \\
\text { control) on older workers' healthy } \\
\text { behaviours and health outcomes. }\end{array}$ & $\begin{array}{l}\text { item Behavioral Risk } \text { Factor } \\
\text { Surveillance System scale to assess } \\
\text { vigorous and moderate PA over a } \\
\text { typical week. }\end{array}$ \\
\hline$[21]$ & $\begin{array}{l}\text { To investigate the feasibility of the } \\
\text { Active Lifestyle system, the adherence } \\
\text { of participants to the training plan and } \\
\text { the effectiveness of motivation } \\
\text { instrument. }\end{array}$ & $\begin{array}{l}\text { Adherence to the exercise plan was } \\
\text { evaluated using the physical activity } \\
\text { performance data collected } \\
\text { automatically by the app during the } \\
\text { study. }\end{array}$ \\
\hline [22] & $\begin{array}{l}\text { To evaluate a web-based computer- } \\
\text { tailored physical activity intervention, } \\
\text { with a specific focus on differences in } \\
\text { tailored advice acceptability, website } \\
\text { usability, and physical activity change } \\
\text { between three age groups. }\end{array}$ & $\begin{array}{l}\text { Using self-reported Active Australia } \\
\text { Survey, which has demonstrated good } \\
\text { validity in previous studies. }\end{array}$ \\
\hline$[23]$ & $\begin{array}{l}\text { To assess user characteristics related to } \\
\text { participation and attrition when } \\
\text { comparing Web-based and print- } \\
\text { delivered tailored interventions and to } \\
\text { provide recommendations in choosing } \\
\text { the appropriate delivery mode for a } \\
\text { particular target audience. }\end{array}$ & $\begin{array}{l}\text { Self-administered Dutch } \\
\text { Questionnaire to Assess } \\
\text { Enhancing Health } \\
\text { (SQUASH) to measure total weekly } \\
\text { days and minutes of PA }\end{array}$ \\
\hline [24] & $\begin{array}{l}\text { To identify user characteristics that } \\
\text { predict initiation and completion of an } \\
\text { online CT lifestyle program and to } \\
\text { study the effect of using a proactive } \\
\text { approach (email reminder) compared to } \\
\text { a reactive approach on program revisits. }\end{array}$ & $\begin{array}{l}\text { Physical activity measured by self- } \\
\text { reported Short Questionnaire to Assess } \\
\text { Health-enhancing physical activity } \\
\text { (SQUASH). }\end{array}$ \\
\hline [25] & $\begin{array}{l}\text { To compare dropout rates of } 2 \\
\text { computer-tailored interventions (a } \\
\text { sequential and a simultaneous } \\
\text { behavioural change strategy) and to } \\
\text { assess which personal characteristics } \\
\text { are associated with completion rates of } \\
\text { the } 2 \text { interventions. }\end{array}$ & $\begin{array}{l}\text { Physical activity measured by self- } \\
\text { reported Short Questionnaire to Assess } \\
\text { Health-enhancing physical activity } \\
\text { (SQUASH). }\end{array}$ \\
\hline [26] & $\begin{array}{l}\text { To examine how members above the } \\
\text { age of } 65 \text { years performed in an } \\
\text { internet-based behavioural weight loss } \\
\text { program, compared to younger } \\
\text { members. }\end{array}$ & $\begin{array}{l}\text { Using self-reported physical activity } \\
\text { data, where participants recorded hours } \\
\text { (h) of physical activity conducted in a } \\
\text { week on the website. }\end{array}$ \\
\hline
\end{tabular}

Furthermore, as shown in Table 2 below, nine studies reported on interventions that were solely developed to enhance physical activity. Six of these studies focus only on an older adult population [14,15, 16, 17, 21,23], while three physical activity interventions developed for a general population [12, 19, 22]. The remaining six studies only described physical activity as sub-components of the interventions, as these studies involved interventions that were not mainly developed to enhance physical activity but to encourage weight loss [26], fall prevention [18], weight maintenance [13], general health assessment [20,24] and health behaviour change [25]. 
Out of nine interventions with physical activity as the main component, three studies utilized objective physical activity measurements [16, 17, 21], four studies utilize subjective measurement $[15,16,19,23]$, while two studies $[12,14]$ utilized both types of measurement. Meanwhile, all of the remaining six studies with physical activity as subcomponents of the interventions only used subjective measurements such as self-reported questionnaires to measure physical activity outcome $[13,18,20$, $26,24,25]$.

In terms of target user groups only seven studies specifically aimed at an older adult population. Four of these studies indicate positive outcomes with increase in physical activity level after intervention $[14,15,16,21]$ whilst two studies had a negative outcome [17, 23]. Albaina et al. [17] shows a decrease in physical activity level at post-intervention compared to pre-intervention phase, while Peels et al. [23] found out that there is no significant difference between physical activities of older adults in a web-delivered compared to a print-delivered group. The remaining one study however, only measured physical activity at a baseline and not after program completion, leaving the effects of the intervention on physical activity of older adults remaining unclear [18].

Meanwhile for eight interventions targeting a general population, six studies indicate positive outcomes where there was an increase in physical activity across all age groups $[12,13,19,20,22,26]$. In fact, two of those studies highlighted that physical activity among older adult participants were found to be higher than among younger participants [13, 26]. Another two interventions however only measured physical activity at a baseline and not after program completion, leaving the effects of both interventions on participants' physical activity inconclusive [24, 25]. Still, both studies did highlight that older participants were more likely to initiate [24], and complete the program's modules proposed by the respective interventions $[25,26]$.

Table 2. Summary of intervention characteristics and physical activity outcomes .

\begin{tabular}{|c|c|c|}
\hline Study & Intervention Characteristics & Physical activity outcome \\
\hline [12] & $\begin{array}{l}\text { The website provides access to } \\
\text { physical activity tracker and listings } \\
\text { of moderate, hard, and very hard } \\
\text { intensity physical activities. } \\
\text { Standardized feedback was provided } \\
\text { via e-mail each week by the principal } \\
\text { investigator. }\end{array}$ & $\begin{array}{l}\text { After } 6 \text { weeks, the median change in total } \\
\text { energy expenditure measured by 7-D PAR } \\
\text { and RT3 accelerometer at baseline declined } \\
\text { in the usual care group compared with no } \\
\text { change in the intervention. The median } \\
\text { VO2max increased } 8.6 \% \text { in the intervention } \\
\text { group and decreased } 1.9 \% \text { in the usual care } \\
\text { group. }\end{array}$ \\
\hline [13] & $\begin{array}{l}\text { Healthy Weight Assistant (HWA), a } \\
\text { web-based application to increase } \\
\text { healthy behaviour in adults with a } \\
\text { healthy weight or slight overweight. }\end{array}$ & $\begin{array}{l}\text { People who are older are more likely to use } \\
\text { the HWA. Using the HWA leads to } \\
\text { improvement in physical activity behaviour. }\end{array}$ \\
\hline [14] & $\begin{array}{l}\text { Join2move is a self-paced 9-week } \\
\text { physical activity program. In the first } \\
\text { week, users select a central activity, } \\
\text { perform a 3-day self-test and } \\
\text { determine a short-term goal for the } \\
\text { next } 8 \text { weeks. Based on those test and }\end{array}$ & $\begin{array}{l}\text { At } 3 \text { months and } 12 \text { months, physical } \\
\text { activity scores in the intervention group } \\
\text { increased by } 1 \% \text { ( } 1 \text { point) and } 6 \% \text { ( } 11 \\
\text { points) compared to baseline. The } \\
\text { intervention group remained stable while } \\
\text { the control group reported a physical }\end{array}$ \\
\hline
\end{tabular}




\begin{tabular}{|c|c|c|}
\hline & $\begin{array}{l}\text { short-term goals, } 8 \text { tailored weekly } \\
\text { modules are automatically generated. }\end{array}$ & $\begin{array}{l}\text { activity reduction of } 37 \text { minutes after } 3 \\
\text { months and } 57 \text { minutes after } 1 \text { year. }\end{array}$ \\
\hline [15] & $\begin{array}{l}\text { Active After } 55 \text { was a multiple-visit } \\
\text { Internet program to enhance } \\
\text { functional ability, mobility, and } \\
\text { physical activity of older adults. } \\
\text { Using text and video messages } \\
\text { integrated with interactive values } \\
\text { clarification and goal-setting } \\
\text { activities, it helped users develop a } \\
\text { self-tailored exercise plan. }\end{array}$ & $\begin{array}{l}\text { At } 3 \text { months, intervention participants } \\
\text { showed significant improvement on } 13 \text { of } \\
14 \text { outcome measures compared to the } \\
\text { control participants. At } 6 \text { months, } \\
\text { intervention participants maintained large } \\
\text { gains compared to the control participants } \\
\text { on all } 14 \text { outcomes measures, suggesting } \\
\text { that the program is potentially effective at } \\
\text { increasing physical activity level of } \\
\text { sedentary older adults. }\end{array}$ \\
\hline [16] & $\begin{array}{l}\text { DirectLife consists of three elements: } \\
\text { (1) an accelerometer-based activity } \\
\text { monitor, (2) a personal website, and } \\
\text { (3) a personal e-coach, who provides } \\
\text { regular updates of the individual's } \\
\text { physical activity status by email and } \\
\text { gives advice to increase physical } \\
\text { activities. }\end{array}$ & $\begin{array}{l}\text { At the ankle, activity counts increased by } \\
46 \% \text { in the intervention group compared to } \\
12 \% \text { in the control group. At the wrist, } \\
\text { activity counts increased by } 11 \% \text { in the } \\
\text { intervention group and } 5 \% \text { in the control } \\
\text { group, indicating that the intervention was } \\
\text { effective in increasing physical activity of } \\
\text { inactive older adults. }\end{array}$ \\
\hline [17] & $\begin{array}{l}\text { Flowie: a persuasive virtual coach } \\
\text { consists of 1) A wireless pedometer } \\
\text { (ActiPED), 2) a laptop and 3) } \\
\text { touchscreen (Tablet) }\end{array}$ & $\begin{array}{l}\text { Number of steps for participant } 1 \text { is higher } \\
\text { in the pre-intervention phase compared to } \\
\text { the intervention phase, probably due to bad } \\
\text { weather conditions. }\end{array}$ \\
\hline [18] & $\begin{array}{l}\text { The website is accessible at } \\
\text { www.balancetraining.org.uk. Each } \\
\text { user advanced through the questions } \\
\text { and advice on the website in the same } \\
\text { sequence, allowing for a direct } \\
\text { comparison of the advice between } \\
\text { intervention and control participants. }\end{array}$ & $\begin{array}{l}\text { SBT level only conducted at baseline, but } \\
\text { not after completion of the program. Thus } \\
\text { effectiveness of this intervention in } \\
\text { enhancing physical activity was unclear. }\end{array}$ \\
\hline [19] & $\begin{array}{l}\text { 1) Tailored Internet, individually } \\
\text { tailored feedback from a computer } \\
\text { expert system generated based on } \\
\text { constructs from the Transtheoretical } \\
\text { Model and Social Cognitive Theory. } \\
\text { 2) Standard Internet program } \\
\text { received access to six currently } \\
\text { available physical activities web site. }\end{array}$ & $\begin{array}{l}\text { Results indicated changes in weekly } \\
\text { physical activity from } 17.24 \text { min (standard } \\
\text { deviation }[S D]=20.72) \text { at baseline to } 139.44 \\
\text { min }(S D=99.20) \text { at } 6 \text { months, to } 104.26 \text { min } \\
(S D=129.14) \text { at } 12 \text { months, suggesting that } \\
\text { significant change in physical activity } \\
\text { behaviour occurred in the first } 6 \text { months. }\end{array}$ \\
\hline [20] & $\begin{array}{l}\text { 1) The COACH, a web-based risk } \\
\text { assessment with personalized health- } \\
\text { improvement action plans and support } \\
\text { from a coach; 2) the RealAge, a web- } \\
\text { based risk assessment with behaviour- } \\
\text { specific modules } 3 \text { ) control group } \\
\text { received printed health-promotion } \\
\text { materials. }\end{array}$ & $\begin{array}{l}\text { At } 6 \text { and } 12 \text { months, } C O A C H \text { participants } \\
\text { showed significant participation in physical } \\
\text { activity }(\mathrm{P}=.05 ; \mathrm{P}=.013) \text { compared to } \\
\text { RealAge and control group. COACH } \\
\text { participants experienced twice the number } \\
\text { of positive outcomes that control } \\
\text { participants experienced. }\end{array}$ \\
\hline [21] & $\begin{array}{l}\text { Active Lifestyle, as software for the } \\
\text { autonomous physical training of } \\
\text { strength and balance for } \\
\text { independently living older adult. }\end{array}$ & $\begin{array}{l}\text { Adherence with the training plans was } 73 \% \\
\text { indicating older adults were more motivated } \\
\text { with the support of the app. }\end{array}$ \\
\hline
\end{tabular}




\begin{tabular}{|c|c|c|}
\hline [22] & $\begin{array}{l}\text { A website-delivered computer- } \\
\text { tailored physical activity intervention. }\end{array}$ & $\begin{array}{l}\text { Although it had significantly lower } \\
\text { perceived Internet self-confidence scores, } \\
\text { the oldest age group had higher increase in } \\
\text { physical activity compared to other age } \\
\text { groups. }\end{array}$ \\
\hline [23] & $\begin{array}{l}\text { Active Plus, adapted web version of a } \\
\text { print-delivered intervention. }\end{array}$ & $\begin{array}{l}\text { The total minutes of moderate to vigorous } \\
\text { physical activity did not differ significantly } \\
\text { between web-based and print-delivered } \\
\text { groups. The print-delivered group had a } \\
\text { significantly higher intention to be } \\
\text { sufficiently physically active }(\mathrm{P}=.03) \text {. }\end{array}$ \\
\hline [24] & $\begin{array}{l}\text { The CT (computer tailored) program } \\
\text { embedded in the online version of } \\
\text { The Monitor (a monitoring tool to } \\
\text { assess the overall level of health in } \\
\text { the Dutch population). }\end{array}$ & $\begin{array}{l}13 \% \text { (275 participants) initiated the } \\
\text { physical activity module and } 55.6 \% \text { of them } \\
\text { (153/275 participants) completed the } \\
\text { module. Older participants more likely to } \\
\text { initiate and completed the module. }\end{array}$ \\
\hline [25] & $\begin{array}{l}\text { The web-based questionnaire } \\
\text { included questions regarding the } \\
\text { participants lifestyle behaviours } \\
\text { (physical activity, fruit and vegetable } \\
\text { consumption, alcohol intake, and } \\
\text { smoking). At the end of the } \\
\text { questionnaire, participants received } \\
\text { information about the tailored } \\
\text { program. In sequential condition, } \\
\text { participant received feedback on one } \\
\text { behaviour whilst in simultaneous } \\
\text { condition, they received feedback on } \\
\text { all behaviours. }\end{array}$ & $\begin{array}{l}\text { Both groups (in sequential and } \\
\text { simultaneous condition) have high rate of } \\
\text { non-completion. Older participants were } \\
\text { more likely to complete the program and } \\
\text { adhered to more health guidelines. } \\
\text { However, as physical activity level only } \\
\text { measured at baseline and not after the } \\
\text { program completion, the effects of } \\
\text { intervention on physical activity is unclear. }\end{array}$ \\
\hline [26] & $\begin{array}{l}\text { Weight club's website, an internet- } \\
\text { based behavioural weight loss } \\
\text { program enabled members to record } \\
\text { their food intake and physical activity } \\
\text { level online and provide appropriate } \\
\text { feedback to encourage weight loss. }\end{array}$ & $\begin{array}{l}\text { Those over the age of } 65 \text { reported a higher } \\
\text { degree of leisure time physical activity } \\
\text { compared to their younger counterparts as } \\
74.4 \% \text { of the men and } 77.3 \% \text { of the women } \\
\text { reached the level of } 4-6 \text { hour a week. }\end{array}$ \\
\hline
\end{tabular}

\section{Discussion}

Web-based interventions specifically developed only to encourage physical activity among older adults were found to be more effective and successful as six-studies indicating positive outcomes $[14,15,16,19,21,22]$ compared to only three positive outcomes for studies with web-based interventions as sub-components or additional features of the web $[13,20,26]$. A possible explanation for this phenomena could be observed in Schulz et al. [25], which investigates the differences between the sequential and simultaneous approach of behaviour change. The study found out that there were higher dropout rates in a simultaneous conditions group compared toa sequential one hence suggesting that targeting one behaviour at a time (physical 
activity only as the main component of the intervention) was more effective in encouraging behavioural change [27].

\section{Physical activity measurements}

The majority of web-based interventions that solely aim to enhance physical activity used objective measures, or a combination of both objective and subjective measures. All interventions with physical activity as subcomponents however only implement subjective measures through self-reported questionnaires. This indicates that the reliability of physical activity data were not critical, as the focus of those studies were mainly on the perceived acceptance [23] or the usability of the web [21, 24] rather then its efficacy in enhancing physical activity among older adults.

Meanwhile several studies have highlighted the limitations of their physical activity measurements as either subjective or objective measurements. As for subjective measurements, although some studies indicate that their questionnaires and instruments have been proven to be validated by previous research $[14,15,23,25]$, its reliability remains debatable as there is no clear evidence as to whether previous research had validated the instruments with older adults as well. This is imperative to acknowledge as older adults may experience cognitive decline and/or have difficulties in recall, particularly if the post-test evaluation using those self-reported questionnaires was conducted long after the intervention was completed (e. g. assessment after 3-months/6-months). Besides, in using subjective measurements, it is imperative for researchers to determine the appropriate length of the questionnaires, as Schneiders et al. [24] found out that a lengthy questionnaire could lead to higher dropout rates among participants. Further, Van der Mark et al. [26] was concerned that self-reported data needs to be verified as there might be false or inaccurate data provided. A study by Bossen et al. [14] proved that unfavorable events could happen as they found out that self-reports from their participants indicated a sign of overestimation of physical activity levels when compared to objective monitoring by an accelerometer. Such imprecision of the self-reported data would not only negatively influence the overall result of the study but also, towards the participants as they will receive personally tailored advice that is not accurate which might result in lower acceptability of the tailored advice [18].

Precautions also should be taken into account in choosing an appropriate device for carrying out objective measurements. Albaina et al. [17] for example, have concerns about the limited sensing capabilities of the pedometer (which could only monitor steps counts in walking) as there is possibility that the system could push users to exercise more, even though they may have already exercised a lot by doing other activities e.g. bicycling, swimming. Moreover, the system was unaware of contextual factors that affected walking levels (e.g. bad weather) that makes running outdoors not possible. Meanwhile, Wjisman et al. [16] who used two accelerometers in their study (ankle- and wrist-accelerometers) surprisingly found that there are differences in daily physical activity levels measured by both wearable devices. It turns out that the ankle-accelerometer recorded significantly higher physical activity compared to the wrist-accelerometer due to the fact that the ankle location is more sensitive to detecting differences in daily physical activities such as cycling behaviour, which had been done strenuously in their studies. Thus, its imperative for researchers to choose 
appropriate objective measurements based on recommended physical activities to be conducted by their respective participants.

\section{Intervention Characteristics}

A study by Peels et al. [23] indicates that printed intervention has higher participation rate $(19 \%)$ among older adults compared to web-based intervention. In fact, the dropout rate was significantly higher in the Web-based intervention group (53\%) compared to the print-delivered intervention $(39 \%, \mathrm{P}<.001)$. Hence, optimal design strategies are imperative to motivate older adults with low intention to continue their participation in web-based health-promoting interventions.

One of the most effective identified design strategies leading to a successful outcome is the integration of tailored feedback, messages or advice that is personalized based on individual needs and preferences [28]. This is due to the fact that tailored advice was associated with greater perceived personal relevance of the recommended physical activities and greater perception that the recommended activities would be good for them [18, 24, 25]. However, as shown in the Schulz study, it is necessary for tailored texts to be shortened or spread over a particular period of time to prevent dropouts due to information overload. This is particularly true in the case of older adults participants who might experience cognitive decline and only be able to process a few pieces of information at a time [29].

The integration of social roles such as virtual coach or online consultation with experts was also found to be influential in establishing trust and confidence towards the system leading to favourable outcomes [30, 31, 32]. Participants of the Albaina et al. [17] study for example indicated that the integration of a virtual coach into Flowie makes them feel motivated to exercise more. The design strategy was notably proven to be effective in Hughes et al. [20], which found that $97 \%$ of the $C O A C H$ group (who are able to communicate online with a coach) underwent a baseline health-risk assessment and completed a health action, compared to $57 \%$ of the RealAge group who were only able to access the Web site and completed the risk assessment. In fact, Schneider et al. [24] stresses the importance of this design strategy stating that the absence of such communication features may lead to dropouts.

Another successful element is the integration of goal settings and action plan which could enhance self-efficacy and confidence levels among older adults [33]. The study by Albaina et al. [17] found out that goal settings enabled participants to observe their progress, leading to an enhancement in self-efficacy and motivational levels as participants perceived the goals to be achievable. Nyman et al. [18] also agrees with the notion, suggesting that an action plan enhanced participants' confidence and selfefficacy in carrying out physical activities leading to an increase in the likelihood of an individual to adopt a new behaviour. Such influence of self-efficacy on health behavioural change had been hypothesized by Social Cognitive Theory, which postulates that, "if individuals have a sense of personal agency or self-efficacy, they can change behaviours even when faced with obstacles" [34].

Besides that, our reviews also found several factors that can be associated with negative outcomes. Apart from Peels et al. [23], which shows older adults tend to choose printed materials over web-based interventions, other negative outcomes unexpectedly were due to methodological issues rather than the inefficacy of the 
interventions. One of issue is that the duration of the evaluation was too short, such that conclusive outcomes could not be made. In Albaina et al. [17] for example which conducted an evaluation only in an 11-day span, revealed negative outcomes as their result indicates a reduction in physical activity at the post-test compared to the pretest phase. The negative result was claimed to be due to bad weather (raining) on subsequent days after the pre-test which restrained participants from doing any outdoors activities (e.g. jogging, walking, running). Besides, as previous research suggests health behaviour change (or in this case, enhanced physical activity levels) might take quite a long time to happen, it is hence necessary for the intervention to be evaluated over a longer period of time. A longitudinal study similar to the one by Nyman et al. [18], which conducted an evaluation over 3 months is recommended. Further, to improve the accuracy of collected data, it is highly recommended for a randomized control trial to be conducted as the presence of a control group would made it easier for researchers to rule out confounding variables such as bad weather conditions [35].

For interventions involving multiple age groups of participants, several of these interventions indicate higher physical activity among older adults compared to their younger counterparts $[13,24,25]$. In fact, two studies indicate higher rates of module initiation and completion among older adult participants compared to younger adults indicating that, older adults have high interest in utilizing web-based applications for their health benefits [24, 25]. Supported by previous studies, Amman et al. [22] believes that this was due to the fact that older adults place greater importance on their health compared to younger adults as they have more leisure time and are able to implement changes into their daily life more easily.

In relation to the Malaysian context, one of the few examples of health systems developed specifically for Malaysian older adults is We Sihat, an interactive digital nutritional educational packaged [36]. The We Sihat application, which was developed based on touch-screen technology integrated with interactive 3D and multimedia elements and designed based on comprehensive design guidelines for the elderly, has been proven to be well accepted and has successfully enhanced nutritional knowledge among Malaysian older adults participants. Although, We Sihat mainly focuses on user acceptance of the use of technology rather than health behaviour change, still, their findings indicates that there is potential for utilizing computing technology to encourage healthy behaviour among the population [36, 37].

In terms of improvement in physical activity levels, an exercise-promotion intervention by Shahar et al. [38] had successfully encourage physical activity among respective older Malays participants. The intervention which was carried out for 12 weeks involving 65 sarcopenic elderly Malays aged 60-74 years old found out that the exercise program was helpful to improve muscle strength and body composition. Unfortunately, their intervention are not web-based, hence requires one-to-one consultations with a practitioner over a period of time. Similar interventions built with web technology however are not yet available. Thus, it is imperative for researchers to now prioritize developing web-based interventions to encourage physical activity among the Malaysian older adult population.

Accordingly, our paper provides an overview of current practices on development and evaluation of web-based physical activity interventions that were mainly conducted in developed countries. It will serve as preliminary literature that would 
assist researchers and designers in determining appropriate design strategies that would potentially lead to successful outcomes.

\subsection{Limitations}

Although this review only involved 15 selected studies, which makes generalization of findings more difficult, we are still able to provide preliminary evidence of the potential of web-based interventions in enhancing physical activity levels among an older adult population. However, pcaution needs to be taken, as some of these selected studies involved other age groups as well.

\section{Conclusions}

The effectiveness of web-based interventions in encouraging physical activity among older adults largely depends on intervention characteristics and underlying design strategies that have been integrated into the system. Our reviews also found that, despite age-related impairments and computer illiteracy experienced in this population, older adults managed to overcome these barriers and exploited the benefits that such web-based interventions can offer them. This has been shown by higher rates of initiation and completion of the modules among older adult participants compared to their younger counterparts. However, as most of these webbased physical activity interventions were conducted in developed countries where public health was well-established and older adult participants tend to be more exposed to technology, future research is necessary to investigate whether similar interventions could help to enhance physical activity levels among older adults of developing countries which are often associated with sedentary behaviour and an unhealthy lifestyle.

Acknowledgments. The work was supported by the Ministry of Science, Technology and Innovation (MOSTI), E-Science Fund research grant (06-01-02-SF1083) and AS was supported by Science Foundation Ireland under grand 13/RC/2289.

\section{References}

1. Arif, M.T. :The Malaysian Health System of the Future in the Context of Globalisation. Jurnal Kesihatan Masyarakat Isu Khas 2002, pp. 1-7 (2002)

2. Rampal, L., Rampal, S., Azhar, M. Z., Rahman, A.R.: Prevalence, Awareness, Treatment and Control of Hypertension in Malaysia: A National Study of 16,440 subjects. Public Health, pp. 11-18 (2008)

3. Samoocha, D., Bruinvels, D.J., Elbers, N.A., Anema, J.R., van der Beek, A.J.: Effectiveness of Web-Based Interventions on Patient Empowerment: A Systematic Review and Meta-Analysis. J Med Internet Res 12(2): e23 (2010) 
4. Jung, M.L., Loria, K.: Acceptance of Swedish E-health Services. J Multidiscip Healthc, pp. 55-63 (2010)

5. Semlitsch, T., Jeitler, K., Hemkens, L.G., Horvath, K., Nagele, E., Schuermann, C., Pignitter, N. et al.: Increasing Physical Activity for the Treatment of Hypertension: A Systematic Review and Meta-Analysis. Sports Medicine (Auckland, N.Z.) 43(10), pp. 1009-1023 (2013)

6. Aalbers, T., Baars, M.A.E., Rikkert, M.G.M.O.: Characteristics of Effective Internetmediated Interventions to Change Lifestyle in People Aged 50 and Older: A Systematic Review. Ageing Res Rev 10(4), pp. 487-97 (2011)

7. Caprani, N., Doyle, J., Grady, M.J.O., Gurrin, C., Connor, N.E.O., Hare, G.M.P.O.: Technology Use in Everyday Life : Implications for Designing for Older Users. In: iHCI 2012: $6^{\text {th }}$ Annual Irish Human Computer Interaction (HCI) Conference (2012)

8. Brox, E., Emilio, J., Hernández, G.: Exergames for Elderly Social Exergames to Persuade Seniors to Increase Physical Activity. In: 5th International Conference on Pervasive Computing Technologies for Healthcare, pp. 546 - 549 (2011)

9. Kim, E. H., Stolyar, A., Lober W. B., Herbaugh, A. L., Shinstrom, S. E., Zierler, B. K., Soh, C. B. et al.: Challenges to Using an Electronic Personal Health Record by a LowIncome Elderly Population. J Med Internet Res 11(4): e44 (2009).

10. Zajicek, M.: Successful and available: interface design exemplars for older users. Interact Comput 16(3), pp. 411-430 (2004)

11. Gusi, N., Prieto, J., Forte, D., Gomez, I., González-Guerrero, J. L.: Needs, Interests, and Limitations for the Promotion of Health and Exercise by a Web Site For Sighted and Blind Elderly People: A Qualitative Exploratory Study. Educ Gerontol 34(6), pp. 449-461 (2008).

12. Bosak, K. A., Yates, B., Pozehl, B. : Effects of an Internet Physical Activity Intervention in Adults with Metabolic Syndrome. West J Nurs Res 32(1), pp. 5-22 (2010)

13. Kelders, S. M., Gemert-pijnen, J. E. W. C. V., Werkman, A., Seydel, E. R.: Usage and Effect of a Web-based Intervention for the Prevention of Overweight: a RCT. Stud Health Technol Inform 160 (PT 1), pp. 28-33 (2010)

14. Bossen, D., Veenhof, C., Van Beek, K. E., Spreeuwenberg, P. M., Dekker, J., De Bakker, D. H. : Effectiveness of a Web-based Physical Activity Intervention in Patients with Knee and/or Hip Osteoarthritis: Randomized Controlled Trial. J Med Internet Res 15(11):e257 (2013)

15. Irvine, A. B., Gelatt, V. A., Seeley, J. R., Macfarlane, P., Gau, J. M. : Web-based Intervention to Promote Physical Activity by Sedentary Older Adults: Randomized Controlled Trial. J Med Internet Res 15(2): e19 (2013).

16. Wijsma, C. A., Westendorp, R. G., Verhagen, E. A., Catt, M., Slagboom, P. E., de Craen, A. J., Mooijaart, S. P. : Effects of a Web-Based Intervention on Physical Activity and Metabolism in Older Adults: Randomized Controlled Trial. J Med Internet Res 15(11):e233 (2013)

17. Albaina, I. M., Visser, T., van der Mast, C. A. P. G., Vastenburg, M. H. Flowie: A Persuasive Virtual Coach to Motivate Elderly Individuals to Walk. In: Proceedings of the 3d International ICST Conference on Pervasive Computing Technologies for Healthcare, pp. 1-7 (2009)

18. Nyman, S. R., Yardley, L.: Website-based Tailored Advice to Promote Strength and Balance Training: An Experimental Evaluation. J Aging Phys Act 17(2), pp.210-22 (2009)

19. Pekmezi, D. W., Williams, D. M., Jennings, E. G., Lewis, B. A., Jakicic, J. M., Marcus, B.H. : Feasibility of Using Computer-tailored and Internet-based Intervention to Promote Physical Activity in Underserved Populations. Telemed J E Health 16(4), pp. 498-503 (2010) 
20. Hughes, S. L., Seymour, R. B., Campbell, R. T., Shaw, J. W., Fabiyi, C., Sokas, R. Comparison of Two Health-Promotion Programs for Older Workers. Am J Public Health 101(5), pp. 883-90 (2011)

21. Silveira, P., van het Reve, E., Casati, F., de Bruin, E. D. : Motivating Physical Exercises in Independently Living Older Adults: A Pilot Study. Int J Med Inform 82(5), pp. 325-334 (2012)

22. Ammann, R., Vandelanotte, C., de Vries, H., Mummery, W. K: Can a Website-delivered Computer-tailored Physical Activity Intervention Be Acceptable, Usable, and Effective For Older People? Health Educ Behav 40(2), pp. 160-170. (2013)

23. Peels, D. A., Bolman, C., Golsteijn, R. H. J., De Vries, H., Mudde, A. N., van Stralen, M. M., Lechner, L.: Differences in Reach and Attrition Between Web-Based and PrintDelivered Tailored Interventions among Adults Over 50 Years of Age: Clustered Randomized Trial. J Med Internet Res 14(6), e179 (2012)

24. Schneider, F., van Osch, L., Schulz, D. N., Kremers, S. P., de Vries, H.: The Influence of User Characteristics and a Periodic Email Prompt on Exposure to an Internet-delivered Computer-tailored Lifestyle Program. J Med Internet Res 14(2), e40 (2012)

25. Schulz, D. N., Schneider, F., de Vries, H., van Osch, L. A. D. M., van Nierop, P. W. M, Kremers, S. P. J.: Program Completion of a Web-based Tailored Lifestyle Intervention for Adults: Differences Between a Sequential and a Simultaneous Approach. J Med Internet Res 14(2), e26 (2012)

26. Van der Mark, M., Jonasson, J., Svensson, M., Linné, Y., Rossner, S., Lagerros, Y.T.: Older Members Perform Better in an Internet-based Behavioral Weight Loss Program Compared to Younger Members. Obes Facts 2(2), pp. 74-79 (2009)

27. Bronswijk, J. E. M. H. V. : Persuasive GERONtechnology: An Introduction. In: Proceedings of the First International Conference on Persuasive Technology for Human Well-being, pp. 183-186. Eindhoven, The Netherlands: Springer-Verlag (2006)

28. Fogg BJ.: Persuasive Technology: Using computers to change what we think and do. San Fransisco, Morgan Kaufmann Publishers (2003)

29. Czaja, S. J., Sharit, J., Lee, C. C., Nair, S. N., Hernández, M. A., Arana, N., Fu, S. H.: Factors Influencing Use of an E-health Website in a Community Sample of Older Adults. J Am Med Inform Assoc 20(2), pp. 277-284 (2012)

30. Calnan, M.W. :Public trust in health care: the system or the doctor? Qual Saf Health Care 13(2), pp. 92-97 (2004)

31. Zulman, D. M., Kirch, M., Zheng, K., An L. C.:Trust in the Internet as a Health Resource Among Older Adults: Analysis of Data From a Nationally Representative Survey. J Med Internet Res 13(1):e19 (2011)

32. Chatterjee, S., Price, A.:Healthy Living with Persuasive Technologies: Framework , Issues, and Challenges. J Am Med Inform Assoc 16(2), pp. 171-178 (2009)

33. Consolvo, S., Klasnja, P., McDonald, D. W., Landay, J. A.: Goal-setting Considerations for Persuasive Technologies that Encourage Physical Activity. In: Proceedings of the 4th International Conference on Persuasive Technology (Persuasive '09), Article No. 8 (2009)

34. National Cancer Institute: Theory at a Glance: A Guide for Health Promotion Practice $\left(2^{\text {nd }}\right.$ Edition). CreateSpace Independent Publishing Platform (2005)

35. Kendall, J. M.: Designing a Research Project: Randomized Controlled Trials and Their Principles. Emerg Med J 20(2), pp. 164-168 (2003)

36. Ali, N. M., Shahar, S., Kee, Y. L., Norizan, A. R., Noah, S. A. M.: Design of an Interactive Digital Nutritional Education Package for Elderly People. Inform Health Soc Care 37(4), pp. 217-229 (2012)

37. Abdullah, M. Y., Salman, A., Razak, N. A., Noor, N. F. M., Malek, J.A.: Issues Affecting the Use of Information and Communication Technology Among the Elderly: A Case Study on JENII. Malaysian Journal of Communication 28(1), pp. 89-96 (2011) 
38. Shahar, S., Kamaruddin, N. S., Badrasawi, M., Sakian, N. I. M., Abd Manaf, Z., Yassin, Z., Joseph, L.: Effectiveness of Exercise and Protein Supplementation Intervention on Body Composition, Functional Fitness, and Oxidative Stress Among Elderly Malays With Sarcopenia. Clin. Interv. Aging 8, pp. 1365-1375 (2013) 